\title{
Al-Ho (Aluminum-Holmium)
}

\section{H. Okamoto}

The Al-Ho phase diagram in [Massalski2] was adopted from [1988Gsc], which depended primarily on the work of [1966Mey]. The form of liquidus was unusually asymmetric around $\mathrm{Al}_{2} \mathrm{Ho}$ and $\mathrm{AlHo}_{2}$ in view of a criterion given by [1993Oka].

This problem was solved in the Al-Ho phase diagram shown in Fig. 1 calculated by [2010Jin]. Although this phase diagram is thermodynamically more plausible than that shown in [Massalski2], phase boundaries deviate more from the experimental data observed by [1966Mey]. Accordingly, experimental confirmation is needed on phase boundaries particularly around the liquidus of $\mathrm{Al}_{2} \mathrm{Ho}$ and $\mathrm{AlHo}_{2}$.

\section{References}

1966Mey: A. Meyer, The System Holmium-Aluminum, J. LessCommon Met., 1966, 10(2), p 121-129, in German

1988Gsc: K.A. Gschneidner Jr., and F.W. Calderwood, The Al-Ho (Aluminum-Holmium) System, Bull. Alloy Phase Diagr., 1988, 9(6), p 684-686

1993Oka: H. Okamoto and T.B. Massalski, Guidelines for Binary Phase Diagram Assessment, J. Phase Equilb., 1993, 14(3), p 316-335

2010Jin: L. Jin, Y.B. Kang, P. Chartland, and C.D. Fuerst, Thermodynamic Evaluation and Optimization of Al-Gd, Al-Tb, Al-Dy, Al-Ho, and Al-Er Systems Using a Modified Quasichemical Model for the Liquid, Calphad, 2010 , 34(4), p 456-466

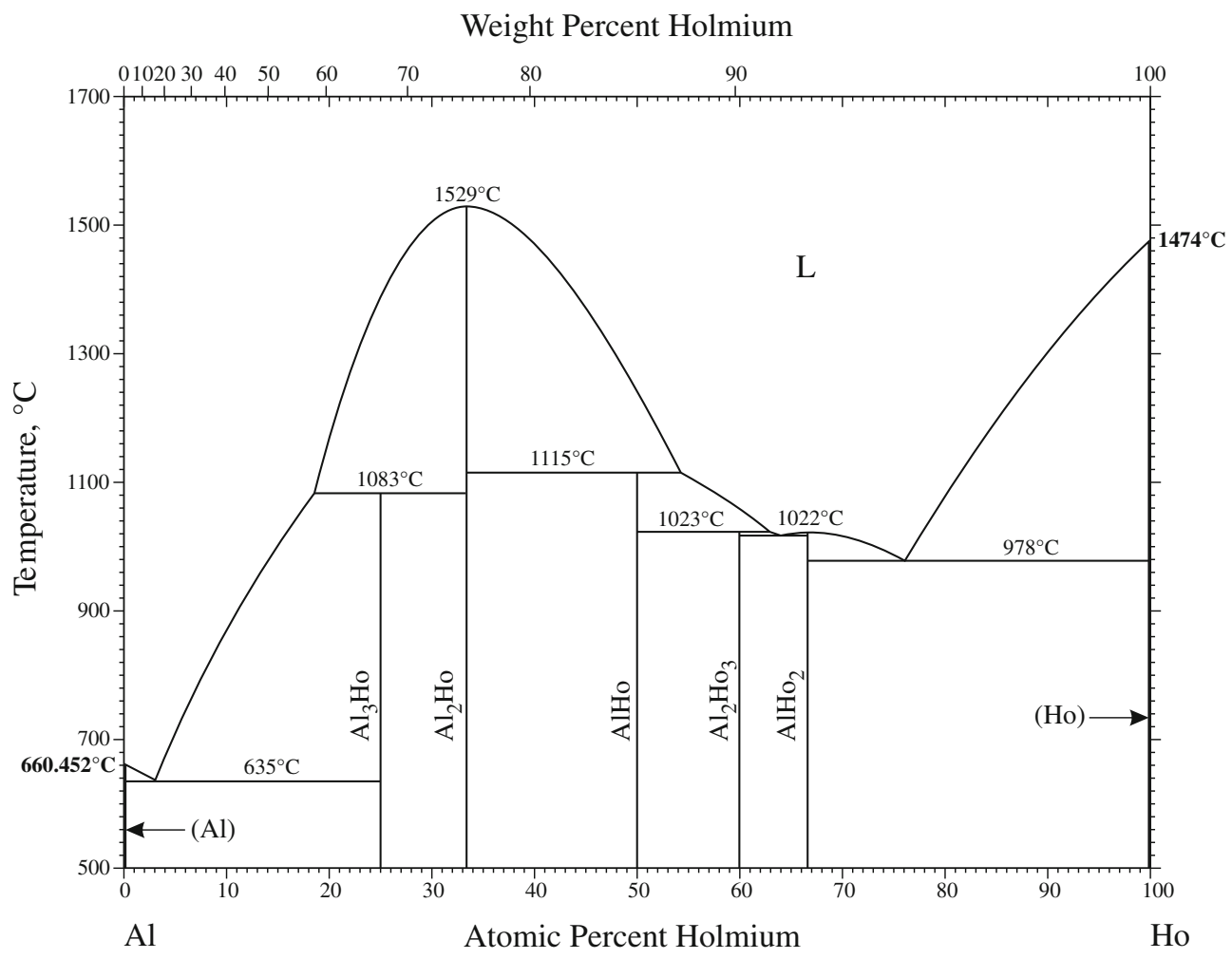

Fig. 1 Al-Ho phase diagram 